\title{
Temperature and curing time affect composite sorption and solubility
}

\author{
Fabrício Luscino Alves de CASTRO'1, Bruno Barbosa CAMPOS², Kely Firmino BRUNO³, Rogério Vieira REGES
}

\author{
1- PhD, Professor, Dental Materials and Operative Dentistry, Paulista University, Goiânia, GO, Brazil. \\ 2- MSc, Assistant Professor, Restorative Dentistry, Paulista University, Goiânia, GO, Brazil. \\ 3- PhD, Professor, Endodontics, Paulista University, Goiânia, GO, Brazil.
}

Corresponding address: Fabrício Luscino Alves de Castro - UNIP, Instituto de Ciências da Saúde, Campus Flamboyant - Rodovia BR 153 - Km 503 - Áreas de 1 a 5, Fazenda Botafogo - Goiânia - GO - Brazil - 74845-090 - e-mail: fabriciocastro.odontogo@unip.br

Received: April 10, 2012 - Modification: January 3, 2013 - Accepted: January 30, 2013

\section{ABSTRACT}

\begin{abstract}
$\mathrm{O}$ bjective: This study evaluated the effect of temperature and curing time on composite sorption and solubility. Material and Methods: Seventy five specimens ( $8 \times 2 \mathrm{~mm})$ were prepared using a commercial composite resin (ICE, SDI). Three temperatures $\left(10^{\circ} \mathrm{C}\right.$, $25^{\circ} \mathrm{C}$ and $60^{\circ} \mathrm{C}$ ) and five curing times ( $5 \mathrm{~s}, 10 \mathrm{~s}, 20 \mathrm{~s}, 40 \mathrm{~s}$ and $\left.60 \mathrm{~s}\right)$ were evaluated. The specimens were weighed on an analytical balance three times: A: before storage (M1); B: 7 days after storage (M2); C: 7 days after storage plus 1 day of drying (M3). The storage solution consisted of $75 \%$ alcohol $/ 25 \%$ water. Sorption and solubility were calculated using these three weights and specimen dimensions. The data were analyzed using the Kruskal-Wallis and Mann-Whitney U Tests $(\alpha=5 \%)$. Results: The results showed that time, temperature and their interaction influenced the sorption and solubility of the composite $(p<0.05)$. At $60^{\circ} \mathrm{C}$, the composite sorption showed an inverse relationship with the curing time $(p<0.05)$. The composite cured for $5 \mathrm{~s}$ showed higher sorption for the $40 \mathrm{~s}$ or $60 \mathrm{~s}$ curing times when compared with all temperatures $(p<0.05)$. Curing times of $20 \mathrm{~s}$ and $40 \mathrm{~s}$ showed similar sorption data for all temperatures $(p>0.05)$. The $60^{\circ} \mathrm{C}$ composite temperature led to lower values of sorption for all curing times when compared with the $10^{\circ} \mathrm{C}$ temperature $(p<0.05)$. The same results were found when comparing $10^{\circ} \mathrm{C}$ and $25^{\circ} \mathrm{C}(p<0.05)$, except that the $20 \mathrm{~s}$ and $40 \mathrm{~s}$ curing times behaved similarly $(p>0.05)$. Solubility was similar at $40 \mathrm{~s}$ and $60 \mathrm{~s}$ for all temperatures $(p>0.05)$, but was higher at $10^{\circ} \mathrm{C}$ than at $60^{\circ} \mathrm{C}$ for all curing times $(p<0.05)$. When the composite was cured at $25^{\circ} \mathrm{C}$, similar solubility values were found when comparing the $5 \mathrm{~s}$ and $10 \mathrm{~s}$ or $20 \mathrm{~s}$ and $40 \mathrm{~s}$ curing times $(p>0.05)$. Conclusion: In conclusion, higher temperatures or longer curing times led to lower sorption and solubility values for the composite tested; however, this trend was only significant in specific combinations of temperature and curing times.
\end{abstract}

Key words: Composite resins. Temperature. Time.

\section{INTRODUCTION}

Since its introduction in the 1960s, composite resins have changed the profile of Restorative Dentistry. In addition to their excellent aesthetic properties, the bonding to enamel and/or dentin guarantees satisfactory longevity and a conservative character to the cavity preparations.

The first composites were chemically activated. However, the development of light-activated composite resins, which began in the 1970s, announced a period of rapid progress in the field of esthetic restorations. As a result of technological advances in recent decades, the optical, physical and mechanical properties of composites have been improved - and they have become the material of choice for direct restorations.

The degree of conversion directly influences the physical and mechanical properties of composite resins ${ }^{11,17,28,29,30}$. A higher conversion of carbon double bonds into simple bonds results in better resin properties, such as hardness, elastic modulus, fracture toughness, tensile strength and wear 
resistance ${ }^{11,14,17}$. However, the resin mechanical properties depend much more on the type of polymer chain and crosslink density formed during the polymerization process ${ }^{11,30}$. The formation of this network occurs during the polymerization and includes a mixture of linear carbon chains, forming a big mush. According to Yap, et al. ${ }^{30}$ (2003), the cross-link density of a polymer system plays an important role in the physical and mechanical properties of the final material.

Cross-linking provides a sufficient number of bridges between linear macromolecules to form a three-dimensional network that decreases the sorption and solubility, increases the strength and stiffness of composite resins, and reduces the permeability of the polymers to solvents due to the decreased capacity and clearances, which swell the polymer chains ${ }^{12,27}$. The degradation of composite resins results in a reduction of their mechanical properties; such as elastic modulus, compressive strength, and the deformation of the material, all which directly affect its clinical use ${ }^{15}$.

The temperature of the resin affects the polymerization process and, consequently, the properties of the polymer formed $1,3,18,22,26$. The temperature at which monomers are polymerized affects the degree of conversion ${ }^{5,9,22,24}$. Although several studies have indicated that an increase in resin temperature improves the mobility of monomers and radicals, resulting in a higher degree of conversion $13,17,18,20,22$, many questions still remain regarding the applications of pre-heated resins. Daronch, Rueggeberg and De Goes ${ }^{5}$ (2005) and Daronch, Rueggeberg and De Goes ${ }^{6}$ (2006) studied the effect of heating a composite resin prior to its curing on the kinetics of polymerization and on the material's properties. They found a higher proportion of maximum conversion and a higher degree of conversion in the heated condition when compared to a resin used at room temperature. Other studies have confirmed these effects $7,9,20,24$. Some authors also found that preheating resins led to the improvement of mechanical properties $^{19,21}$ and lower viscosity with better adaptation to the cavity preparation $4,8,13,19$.

It is known that both sorption and solubility are indirect measures of the curing degree of polymers, i.e., they are measures of the degree of cross linking (number of cross links) of a polymer. The more cross-linked a polymer is, the lower its sorption and solubility and therefore it will have better properties ${ }^{11,12,27,28-30}$.

As noted earlier, pre-heating of a composite increases the degree of conversion of monomers into polymers. In theory, this would decrease the sorption and solubility of the material. To date, there is no scientific study proving this fact; therefore, studies on this topic can bring greater clarity regarding the influence of pre-heating a composite in its sorption and solubility properties. Furthermore, pre-heating could be advantageous on restoring the properties of cooled composites. The refrigerated storage and immediate use of the material after removal from the refrigerator can cause the material to achieve low degrees of conversion and entanglement of small chains, which leads to increased sorption and solubility. The literature has recommended to keep the composite outside the refrigerator for a period of time before using it, so that it reaches room temperature ${ }^{5,7,23}$.

Thus, the objective of this current study was to investigate the influence of pre-heating a composite on the sorption and solubility properties of the material stored in a solution of ethanol/ water $(75 \% / 25 \%)$. Changes in curing time were also investigated. The independent variables considered were the temperature of the composite and cure time. The null hypothesis tested was that the composite pre-curing temperature and curing time did not influence the sorption and solubility of the material. The curing times investigated were $5 \mathrm{~s}, 10 \mathrm{~s}, 20 \mathrm{~s}, 40 \mathrm{~s}$ and $60 \mathrm{~s}$; and the material temperatures evaluated were: $10^{\circ} \mathrm{C}$ (cooling condition), $25^{\circ} \mathrm{C}$ (room temperature) and $60^{\circ} \mathrm{C}$ (resin pre-heated).

\section{MATERIAL AND METHODS}

Seventy five $8 \mathrm{~mm}$ wide $\times 2 \mathrm{~mm}$ deep specimens were prepared using a commercial composite (ICE, SDI Limited, Bayswater, Victoria, Australia), shade A2, and a metallic matrix. The 75 specimens were obtained according to the different experimental conditions adopted for this study, as presented in Figure 1 .

The composite was inserted into the metallic

\begin{tabular}{|c|c|}
\hline Curing Time (s) & Composite Temperature $\left({ }^{\circ} \mathbf{C}\right)$ \\
\hline \multirow{2}{*}{5} & 10 \\
& 25 \\
\multirow{3}{*}{10} & 60 \\
\hline \multirow{3}{*}{20} & 10 \\
& 25 \\
& 60 \\
\hline \multirow{3}{*}{40} & 10 \\
& 25 \\
& 60 \\
\hline \multirow{2}{*}{60} & 10 \\
& 25 \\
& 60 \\
\hline
\end{tabular}

Figure 1- Experimental design $(\mathrm{N}=5)$ 
matrix positioned on a heater for the pre-heating condition; in a refrigerator for the refrigerated condition; or at room temperature. The material was inserted using a syringe (Centrix, DFL Indústria e Comércio SA, Rio de Janeiro, RJ, Brazil). A polyester strip and a glass slide were positioned over the inserted composite and the composite was photo cured using a LED curing unit (Radii Cal, SDI Limited, Bayswater, Victoria, Australia) with the light tip put in contact with the glass slide to standardize the curing distance. The time of curing was $5 \mathrm{~s}, 10 \mathrm{~s}, 20 \mathrm{~s}, 40 \mathrm{~s}$ and $60 \mathrm{~s}$, according to the experimental conditions. The curing unit had its energy density monitored during the experimental procedures using a radiometer. The temperature of the composite was confirmed before each photopolymerization using an infrared thermometer (G-Tech, Model IR1DB1 Accumed Produtos MédicoHospitalares LTDA, Duque de Caxias, RJ, Brazil) and the composite was not cured until it reached one of the experimental temperatures investigated $\left(10^{\circ} \mathrm{C}\right.$, $25^{\circ} \mathrm{C}$ or $60^{\circ} \mathrm{C}$ ).

The heater used in this study to pre-heat the composite was developed specifically for this investigation. The device consisted of a wood box which contained two $100 \mathrm{~W}$ incandescent lamps, which were responsible for heat generation. The box had two compartments, separated by a metallic plate. The inferior compartment had its walls covered with mirrors to preserve the generated heat. The superior compartment was empty and had three holes on the top surface where a digital thermometer (Model MV-363, Minipa Indústria e Comércio Ltda., São Paulo, SP, Brazil) to control the box temperature; the metallic matrix; and the Centrix syringe loaded with composite were positioned, from right to left.

Soon after the specimens were prepared, they were put inside amber glasses and the glasses were stored in a desiccator with silica gel, at $37^{\circ} \mathrm{C}$, for $24 \mathrm{~h}$. The specimens were then weighed using an analytical balance (Model AG200, Gehaka, Indústria e Comércio Eletro Eletrônica, São Paulo, SP, Brazil) and the values were recorded as M1. After that, the specimens were stored in $1.5 \mathrm{ml}$ of a $75 \%$ alcohol $/ 25 \%$ water solution for 7 days, at $37^{\circ} \mathrm{C}$. After one week of storage, the specimens were weighed again and the measurement obtained was called M2. Again the specimens were stored in dry conditions as described for M1 mass the M3 mass was found.

The resin specimens were measured using a digital caliper (DIGIMATIC CALIPER ${ }^{\circledR}$, Mitutoyo Absolute - serial number BB071467, Tokyo, Japan) to obtain the radius and the height. Four equidistant points were measured for both radius and height and the mean found from these points were used to calculate the volume of each specimen $\left(V=n r^{2} \mathrm{X}\right.$ h). With the calculation of volume, it was possible to find both sorption and solubility using the following formulas:

Sorption in Alcohol/Water - A/Wsp=M2-M3/V

Solubility in Alcohol/Water- A/WsI= M1-M3/V

Where:

M1 - mass of the specimen ( $\mu \mathrm{g})$, after $24 \mathrm{~h}$ of desiccation

M2 - mass of the specimen $(\mu \mathrm{g})$, after one week of storage in water/alcohol

M3 - mass of the specimen ( $\mu \mathrm{g})$, after one week of storage in water/alcohol plus one day of desiccation

$\mathrm{V}$ - Volume of the specimen $\left(\mathrm{mm}^{3}\right)$

Data obtained was analyzed using the following tests: 1-Kruskal-Wallis Test, to compare temperatures, curing times and the interaction between the variables; 2 - Mann-Whitney U test, to do pair-wise post-hoc comparisons. The significance was set at $5 \%$ for all analyses.

\section{RESULTS}

\section{Sorption}

Both variables, as well their interaction, influenced the composite sorption $(p<0.05)$. Since the various temperatures and curing times affected the sorption in different ways, depending on the specific combination with these two variables, the effect of each variable alone lost importance for the interaction between the two variables.

The comparison among curing times at each temperature showed that sorption increased with decreasing curing time only when at $60^{\circ} \mathrm{C}(p<0.05)$. For the other temperatures, sorption decreased with curing time, but this difference was not statistically significant for all curing times. The curing times of $20 \mathrm{~s}$ and $40 \mathrm{~s}$ showed similar sorption data for all temperatures $(p>0.05)$. Conversely, the composite cured for $5 \mathrm{~s}$ showed higher sorption when compared with curing at $40 \mathrm{~s}$ or $60 \mathrm{~s}$ for all temperatures $(p<0.05)$. The $10 \mathrm{~s}$ curing time gave higher sorption values than the $20 \mathrm{~s}$ time at the $25^{\circ} \mathrm{C}$ and $60^{\circ} \mathrm{C}$ temperatures $(p<0.05)$, instead of being similar to the values obtained at $10^{\circ} \mathrm{C}$ ( $p>0.05)$ (Figure 2).

The comparison among temperatures at each curing time showed that the $60^{\circ} \mathrm{C}$ composite temperature led to lower values of sorption for all curing times $(p<0.05)$ when compared with the $10^{\circ} \mathrm{C}$ temperature. The same results were found when comparing $10^{\circ} \mathrm{C}$ and $25^{\circ} \mathrm{C}(p<0.05)$, except for the $20 \mathrm{~s}$ and $40 \mathrm{~s}$ curing times, where similar results were found $(p>0.05)$. The sorption for specimens cured at $5 \mathrm{~s}, 10 \mathrm{~s}$ and $20 \mathrm{~s}$ curing times were similar between $25^{\circ} \mathrm{C}$ and $60^{\circ} \mathrm{C}(\mathrm{p}<0.05)$; however, at $40 \mathrm{~s}$ and $60 \mathrm{~s}$ the sorption values were found to be higher with the composite used at room 


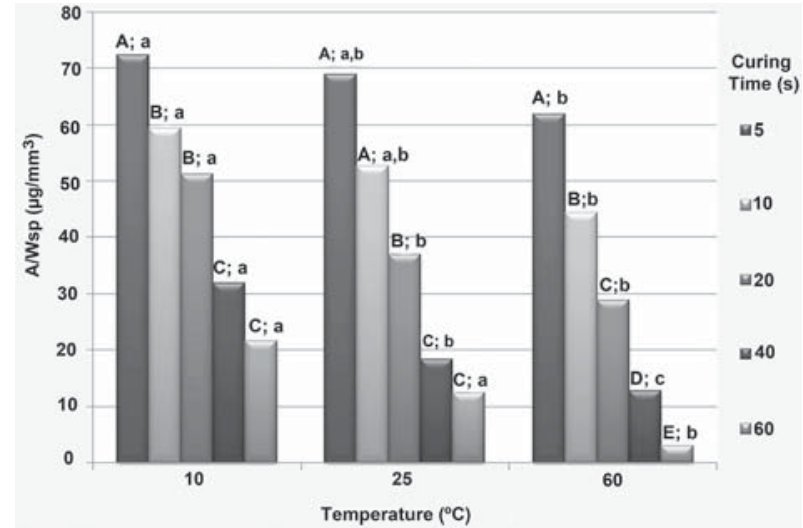

Figure 2- Comparison among values of composite sorption cured at different times and temperatures using the Mann-Whitney $U$ test. Different letters indicate statistically significant differences when comparing both curing times at each temperature (uppercase letters) and temperatures at each curing time (lowercase letters) $(p<0.05)$

temperature than for the pre-heated condition $(p<0.05)$ (Figure 2).

\section{Solubility}

Temperature, curing time and their interaction affected the solubility $(p<0.05)$. Similarly to sorption, only the results of the interaction between the variables are presented.

When comparing curing times at each temperature, solubility was found to be similar between $40 \mathrm{~s}$ and $60 \mathrm{~s}$ for all temperatures ( $p>0.05)$. When the composite was cured at $25^{\circ} \mathrm{C}$, similar solubility values were found when comparing either the $5 \mathrm{~s}$ and $10 \mathrm{~s}$ or $20 \mathrm{~s}$ and $40 \mathrm{~s}$ curing times $(p>0.05)$. The opposite was found for the composite cured at $10^{\circ} \mathrm{C}$ or $60^{\circ} \mathrm{C}$, with higher solubility for 5 $\mathrm{s}$ and $20 \mathrm{~s}$ when compared with the $10 \mathrm{~s}$ and 40 $s$ curing times, respectively $(p>0.05)$. Indeed, at $10^{\circ} \mathrm{C}$ and $60^{\circ} \mathrm{C}$, the $5 \mathrm{~s}$ curing time showed the highest solubility values $(p<0.05)$. The composite cured at $10^{\circ} \mathrm{C}$ showed similar values of solubility when comparing the $10 \mathrm{~s}$ and $20 \mathrm{~s}$ curing times ( $p>0.05)$, but higher solubility values for the $10 \mathrm{~s}$ curing time versus the $20 \mathrm{~s}$ curing time when the composite was cured at $25^{\circ} \mathrm{C}$ or $60^{\circ} \mathrm{C}$ (Figure 3 ).

When comparing temperatures for each curing time, the solubility was found to be higher at $10^{\circ} \mathrm{C}$ than at $60^{\circ} \mathrm{C}$ for all curing times $(p<0.05)$. At the $10 \mathrm{~s}$ and $60 \mathrm{~s}$ curing times, the composite presented solubility data that was similar for the $10^{\circ} \mathrm{C}$ and $25^{\circ} \mathrm{C}$ temperatures $(\mathrm{p}>0.05)$, but different for the $25^{\circ} \mathrm{C}$ and $60^{\circ} \mathrm{C}$ ones, with lower values for the highest temperature $(p<0.05)$. At the $5 s, 20 s$ and $40 \mathrm{~s}$ curing times, the composite showed higher solubility value for the material at $10^{\circ} \mathrm{C}$ than for the material at $25^{\circ} \mathrm{C}(\mathrm{p}<0.05)$. Similar solubility values were found when comparing the $25^{\circ} \mathrm{C}$ and

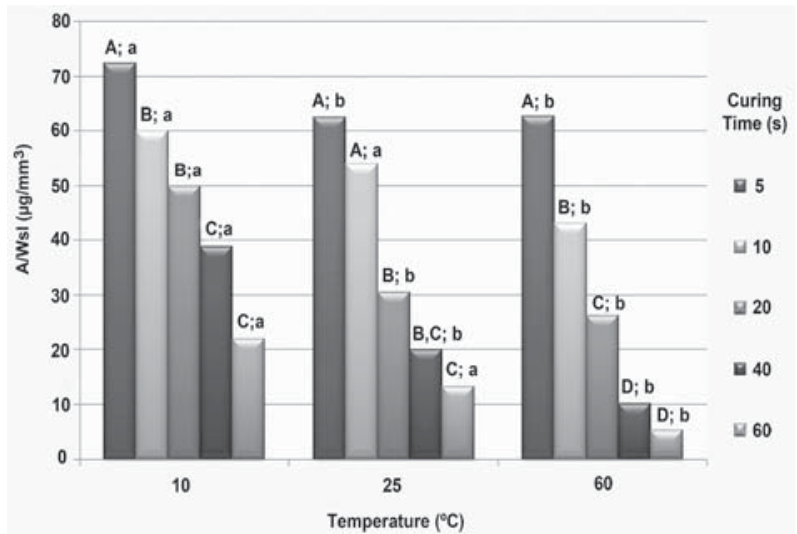

Figure 3- Comparison among values of composite solubility cured at different times and temperatures using the Mann-Whitney $U$ test. Different letters indicate statistically significant differences when comparing both curing times at each temperature (uppercase letters) and temperatures at each curing time (lowercase letters) $(p<0.05)$

$60^{\circ} \mathrm{C}$ temperatures $(p>0.05)$ at these three times (Figure 3).

\section{DISCUSSION}

Several factors related to the chemistry and structure of the polymer networks are important in determining the extent to which a material will be affected by the surrounding aqueous medium $^{12}$. Important chemical characteristics include hydrophilicity of the polymer and the differences in solubility parameters between the polymer and solvent ${ }^{15}$. Structural parameters include the density and porosity of the crosslinked network ${ }^{12,27}$. These properties can also be influenced by the amount and type of charged inorganic particles present in the material ${ }^{12}$. While the composition of the polymer used in the current study was standardized, only one material was tested, the current results are discussed based on the variables introduced in the study, polymerization time and temperature.

According to the present results, curing time and temperature of the composite, as well the interaction of these two variables, significantly affected the sorption and solubility. It seems unreasonable to discuss the results found for the effect of each factor separately, since the data varied according to the combinations of time and temperature.

With regards to sorption, the means found increased for each composite temperature as curing times decreased: longer curing times led to less solvent being incorporated into the composite. Composites that were activated for longer periods of time generally presented a 
higher degree of conversion of monomers into a polymer 2,25 , and consequently a greater degree of entanglement between linear chains, leading to lower values of sorption. This higher degree of conversion led to fewer hydrophilic sites in the material, i.e., a lower chemical affinity of the polymer with the solvent (least amount of unreacted monomers present) and also less space available for penetration of the solvent between the polymer chains (higher cross-linking), leading to less sorption. Although sorption decreased with higher curing times, these differences were significant for all curing times only at $60^{\circ} \mathrm{C}$. It seems that the differences in sorption are more prone to be detected with higher temperatures. The same seems to happen at the extreme curing times, since the sorption values for the $5 \mathrm{~s}$ curing time was higher at all temperatures when compared with the $40 \mathrm{~s}$ and $60 \mathrm{~s}$ times. The composite cured for $40 / 60$ $\mathrm{s}$ and at temperatures approaching $60^{\circ} \mathrm{C}$ probably reaches the maximum amount of cross-linking and curing rate, thereby reducing its sorption. This is confirmed when the sorption values found for each temperature are compared at the five curing times tested. At $60^{\circ} \mathrm{C}$, lower values of sorption were presented for all curing times when compared to the sorption values found with the $10^{\circ} \mathrm{C}$ temperature. The energy provided by heating the system increases the mobility of the monomers, increasing the frequency of collisions of reactive species and allowing subsequent monomer conversions before the polymer reaches self-deceleration, thereby increasing the degree of conversion, which might have been responsible for the lower sorption values found at $60^{\circ} \mathrm{C}^{5,6,22}$. However, this warming did not seem to favor the degree of conversion of the polymer formed when comparing the $10^{\circ} \mathrm{C}$ and $25^{\circ} \mathrm{C}$ temperatures at the curing times of $20 \mathrm{~s}$ and $40 \mathrm{~s}$ or $25^{\circ} \mathrm{C}$ and $60^{\circ} \mathrm{C}$ and the $5 \mathrm{~s}, 10 \mathrm{~s}$ and $20 \mathrm{~s}$ curing times, since there were no statistically significant differences between these temperatures. Similarly to what happened for temperature, it seems that the differences in sorption are more prone to be detected with extreme curing times ( $5 \mathrm{~s}$ and $60 \mathrm{~s}$ ).

There is some controversy in the literature regarding the ability of using pre-heating to generate a higher degree of conversion of monomers into a polymer. While some authors found a higher degree of conversion with a preheated resin $5,6,7,9,24$ other authors found no differences ${ }^{13}$. Lohbauer, et al. ${ }^{16}$ (2009) found no differences in the degree of conversion of a commercial composite when comparing $39^{\circ} \mathrm{C}, 54^{\circ} \mathrm{C}$ with $68^{\circ} \mathrm{C}$ curing temperatures; however, when the temperature was reduced to $10^{\circ} \mathrm{C}$, the degree of conversion on the top surfaces was significantly lower (29.9\%). These contradictions may be related to the different types of composites evaluated in these various studies. Quantity, size and distribution of charged particles, type and combinations of resin monomers used, the polymerization initiator used, the presence of polymerization inhibitors, color, and opacity of the material are all factors that can influence the ability of a composite to polymerize $2,22,27$. Moreover, composites with different compositions may take different times to reach stable temperatures, since the inorganic particles and organic resins function as thermal insulators ${ }^{4}$. Additionally, the heating method used in the various studies may also be responsible for the differences found in the literature. Daronch, et al. ${ }^{7}$ (2006) showed that the temperature of the material falls $50 \%$ in the first 2 minutes after removal of the heat source. In the present study, the material was polymerized directly in the heating device in order to avoid this problem. Further investigations should be done to clarify these aspects.

When comparing the solubility values for the curing times at each temperature, the values increased with decreasing curing times for all temperatures, although the differences were not always statistically significant. These results were significant for the material heated to $60^{\circ} \mathrm{C}$ and the differences became statistically significant, except when the $40 \mathrm{~s}$ and $60 \mathrm{~s}$ curing times were compared. It seems that, for the solubility, a curing time of $40 \mathrm{~s}$ is enough to provide better properties for the evaluated resin. At extreme temperatures $\left(10^{\circ} \mathrm{C}\right.$ and $\left.60^{\circ} \mathrm{C}\right)$, the composite solubility was high when using the $5 \mathrm{~s}$ time when compared to all other temperatures. When comparing temperatures at each curing time, it can be seen that the solubility was higher at $10^{\circ} \mathrm{C}$ than at $60^{\circ} \mathrm{C}$ for all curing times, similar to what was found for the sorption. The same hypothesis is raised, as it seems that solubility is more prone to be detected at the extremes of both curing time and temperature.

As shown above, for both sorption and solubility, curing times of $5 \mathrm{~s}$ were statistically different when compared to curing times of $60 \mathrm{~s}$, while temperatures of $10^{\circ} \mathrm{C}$ were always statistically different when compared to $60^{\circ} \mathrm{C}$. Conversely, the effect of other combinations and times did not show a clear trend. It can be speculated that, if longer storage times would be used, it would be possible to see differences in the sorption/solubility behavior of the composite. Water can cause structural damage by passive hydrolysis, which in turn can lead to more water uptake, thus creating chain scission; therefore, these effects can be pronounced when the composite is challenged repeatedly by an aqueous medium ${ }^{10,12,15}$. Future studies using storage times in aqueous medium for longer than 7 days should be performed.

The rationale behind the evaluation of temperatures as low as $10^{\circ} \mathrm{C}$, both for sorption 
and solubility, is the use of refrigerated materials. Daronch, et al. ${ }^{7}$ (2006) had shown that the clinician should wait at least 11 minutes before using composite stored at $3.5 \pm 0.1^{\circ} \mathrm{C}$. Osternack, et al. ${ }^{23}$ (2009) showed similar top surface hardness values for the groups tested at room temperature and 15 minutes after removal from the refrigerator. If the option is the use of the technique of preheating, this seems to restore the characteristics of the material, at least with respect to the values of sorption and solubility.

\section{CONCLUSIONS}

Considering the experimental conditions and limitations in the current study, it can be concluded that:

1- Both temperature and curing time, as well their interaction, influenced the sorption and solubility of the material tested, therefore, the null hypotheses were rejected;

2- Longer curing times and higher temperatures led to lower values of sorption and solubility, but these differences were only significant for specific combinations of temperatures and curing times.

\section{ACKNOWLEDGMENTS}

This study was supported by the Post-Graduation and Research Vice-Rectory of the Paulista University - UNIP, grant 7-04-716/2009.

\section{REFERENCES}

1- Bausch JR, Lange C, Davidson CL. The influence of temperature on some physical properties of dental composites. J Oral Rehabil. 1981;8:309-17.

2- Caughman WF, Rueggeberg FA, Curstis JW Jr. Clinical guidelines for photocuring restorative resins. J Am Dent Assoc. 1995;126:1280-2.

3- Cook WD, Simon GP, Burchill PJ, Lau M, Fitch TJ. Curing kinetics and thermal properties of vinyl ester resins. J Appl Polym Sci. 1997;64:769-81.

4- Costa JB, Hilton TJ, Swift EJ Jr. Preheating composites. J Esthet Rest Dent. 2011;23:269-75.

5- Daronch M; Rueggeberg FA, De Goes MF. Monomer conversion of pre-heated composite. J Dent Res. 2005;84:663-7.

6- Daronch M, Rueggeberg FA, De Goes MF, Giudici R. Polymerization kinectics of pre-heated composite. J Dent Res. 2006;85:38-43.

7- Daronch M, Rueggeberg FA, Moss L, De Goes MF. Clinically relevant issues related to preheating composites. J Esthet Restor Dent. 2006;18:340-50.

8- Deb S, Di Silvio L, Mackler HE, Millar BJ. Pre-warming of dental composites. Dent Mater. 2011;27:e51-9.

9- El-Korashy DI. Post-gel shrinkage strain and degree of conversion of pre-heated composite resin cured using different regimens. Oper Dent. 2010;35:172-9.

10- Fan PL, Edahl A, Leung RL, Stanford JW. Alternative interpretations of water sorption values of composite resins. J Dent Res. 1985;64:78-80.

11- Ferracane JL. Correlation between hardness and degree of conversion during the setting reaction of unfilled dental restorative resins. Dent Mater. 1985;1:11-4.

12- Ferracane JL. Hygroscopic and hydrolytic effects in dental polymer networks. Dent Mater. 2006;22:211-22.

13- Froes-Salgado NR, Silva LM, Kawano $Y$, Francci C, Reis A, Loguercio AD. Composite pre-heating: effects on marginal adaptation, degree of conversion and mechanical properties. Dent Mater. 2010;26:908-14

14- Ge J, Trujillo M, Stansbury J. Synthesis and photopolymerization of low shrinkage methacrylate monomers containing bulky substituent groups. Dent Mater. 2005;21:1163-9.

15- Ito S, Hashimoto M, Wadgaonkar B, Svizero N, Carvalho RM, Yiu C, et al. Effect of resin hydrophilicity on water sorption and changes in modulus of elasticity. Biomaterials. 2001;26:6449-59. 16- Lohbauer U, Zinelis S, Rahiotis C, Petschelt A, Eliades G. The effect of composite resin pre-heating on monomer conversion and polymerization shrinkage. Dent Mater. 2009;25:514-9.

17- Lovell LG, Lu H, Elliot JE, Stansbury JW, Bowman CN. The effect of cure rate on the mechanical properties of dental resins. Dent Mater. 2001;17:504-11.

18- Lovell LG, Newman SM, Bowman CN. The effects of light intensity, temperature, and comonomer composition on the polymerization behavior of dimethacrylate dental resins. J Dent Res. 1999;78:1469-76.

19- Lucey S, Lynch CD, Ray NJ, Burke FM, Hannigan A. Effect of pre-heating on the viscosity and microhardness of a composite resin. J Oral Rehab. 2010;37:278-82.

20- Mundim FM, Garcia LF, Cruvinel DR, Lima FA, Bachmann L, Pires-de-Souza FC. Color stability, opacity and degree of conversion of pre-heated composites. J Dent. 2011;39(Suppl. 1):e25-9.

21- Muñhoz CA, Bond PR, Sy-Muñoz J, Tan D, Peterson J. Effect of pre-heating on depth of cure and surface hardness of lightpolymerized composite resins. Am J Dent. 2008;21:215-22.

22- Nie J, Lindén LA, Rabek JF, Fouassier JP, Morlet-Savary F, Scigalski $F$, et al. A reappraisal of the photopolymerization kinetics of triethyleneglycol dimethacrylate initiated by camphorquinone-n, $\mathrm{n}$-dimethyl-p-toluidine for dental purposes. Acta Polymer. 1998;49:145-61.

23- Osternack FH, Caldas DBM, Rached RN, Vieira S, Platt JA, Almeida JB. Impact of refrigeration on the surface hardness of hybrid and microfilled composite resins. Braz Dent J. 2009;20:427.

24- Prasana N, Pallavi RY, Kavitha S, Lakshmi NL. Degree of conversion and residual stress of preheated and room-temperature composites. Indian J Dent Res. 2007;18:173-6.

25- Rueggeberg FA, Caughman WF, Curtis JW Jr, Davis HC. Factors affecting cure at depths within light activated composite resins. Am J Dent. 1993;6:91-5.

26- Santana IL, Mendes JG Júnior, Corrêa CS, Gonçalves LM, Souza EM, Souza RC. Effects of heat treatment on the microhardness of direct composites at different depths of restoration. Rev Odonto Cienc. 2012;27:36-40.

27- Sideridou I, Tserki V, Papanastasiou G. Study of water sorption solubility and modulus of elasticity of light-cured dimethacrylatebased dental resins. Biomaterials. 2003;24:655-65.

28- Soh MS, Yap AUJ. Influence of curing modes on crosslink density in polymer structures. J Dent. 2004;32:321-6.

29- Witzel MF, Calheiros FC, Gonçalves F, Kawano Y, Braga RR. Influence of photoactivation method on conversion, mechanical properties, degradation in ethanol and contraction stress of resinbased materials. J Dent. 2005;33:773-9.

30- Yap AU, Soh MS, Han TT, Siow KS. Influence of curing lights and modes on cross-link density of dental composites. Oper Dent. 2004;29:410-5. 